\title{
Publication Activity and Impact of the International Pediatric Simulation Society Cureus Channel: 2014 to 2018
}

Taylor Sawyer ${ }^{1}$, Edward J. Rovera ${ }^{2}$

1. Pediatrics, University of Washington School of Medicine, Seattle, USA 2. Medical Education and Simulation, San Francisco State University, San Francisco, USA

$\square$ Corresponding author: Edward J. Rovera, edrovera@sfsu.edu

Disclosures can be found in Additional Information at the end of the article

\section{Abstract}

\section{Introduction}

In November 2013, the International Pediatric Simulation Society (IPSS) launched a channel on Cureus.com. We performed the following analysis to examine the use of the channel, the reach of its publications, and their impact within the medical literature.

\section{Methods}

The IPSS Cureus channel's Administrative Dashboard was used to collect data on manuscript type, manuscript submission date, publication date, total views, and total downloads for each article from publication date through December 31, 2018. Web of Science and Google Scholar were used to determine which channel publications had been cited during the study period, and those citations were reviewed to develop an estimate of the global reach of the publications.

\section{Results}

A total of 15 articles were published via the IPSS Cureus channel from April 18, 2014 to December 31, 2018, with a mean time between submission and publication of 46 days. These articles have been viewed an average of 736 times per article. The PDF download rate averaged 446 per article. These 15 articles have been cited a total of 37 times, averaging 2.5 citations per article. The sources for those citations were published in English (29), Spanish (4), Portuguese (2), Arabic (1), and Ukrainian (1).

\section{Conclusion}

Received 01/28/2019

Review began 02/06/2019 Review ended 02/12/2019 Published 02/13/2019

(c) Copyright 2019

Sawyer et al. This is an open access article distributed under the terms of the Creative Commons Attribution License CC-BY 3.0., which permits unrestricted use, distribution, and reproduction in any medium, provided the original author and source are credited.
Publications on the IPSS Cureus channel have a clear impact, in terms of the number of views, number of downloads, citation counts, and global reach. The channel also offers a rapid publication cycle. Further education in the pediatric simulation community on the use of the channel and promotion of the benefits of this resource for scholarships are warranted.

Categories: Medical Simulation, Pediatrics, Pediatric Surgery

Keywords: bibliometrics, scientometrics, simulation, professional development, scholarship, pediatrics, pediatric simulation

\section{Introduction}


In 2012, the International Pediatric Simulation Society (IPSS, the "Society") began discussions with Cureus.com, to develop a portal allowing IPSS members to publish their pediatric simulation work. Since 2014, IPSS members have been able to publish their work on the IPSS Cureus channel (www.cureus.com/channels/ipss). Selected Society members perform an editorial review on all articles submitted through the Society's channel. This service is provided at no cost to IPSS members as Cureus has no associated publication fees.

All publications on the IPSS Cureus channel are indexed in PubMed Central, the largest repository of biomedical literature in the world [1]. In turn, PubMed Central is itself indexed in Web of Science (WOS), one of the two largest multi-discipline repositories of scholarly data currently in existence [2].

In order to better understand the usage of the channel, the authors conducted the following study to examine the publication activity and impact of the articles published on the channel. Our specific aim was to attempt to answer the question: What are the publication activity and scholarly impact of the IPSS Cureus channel?

\section{Materials And Methods}

Publication activity on the IPSS Cureus channel was analyzed using the channel's Administrative Dashboard. Data on views and downloads were collected from April 18, 2014 to December 31, 2018 (55 months). Manuscript type, manuscript submission date, publication date, total views, and total downloads for each article were analyzed. Since the longer an article was able to be viewed or downloaded would increase its chances of being viewed or downloaded, the number of views and downloads was measured against the length of time the article had been published in order to give a more accurate measurement of the interest generated by each publication.

The Administrative Dashboard was used to perform an analysis of the IPSS Cureus channel's publication cycle. The dashboard provides the dates of all events pertaining to the publication cycle of any manuscript. The overall length of time between submission and final publication was determined, as were the time points between key steps in the process. The total time from submission to publication was broken into four distinct phases:

1. First editorial review: Once the submitting author requests a manuscript to go into Peer Review, the IPSS Cureus channel editors and one of the Cureus editorial staff perform separate editorial reviews in sequence. The manuscript must pass both editorial reviews to be moved forward to Peer Review.

2. Peer review: This is the length of time the manuscript is being reviewed by members of the Cureus community and the authors are responding to the recommendations of the reviewers. When the authors feel they have answered the reviewers' questions, the submitting author requests publication.

3. Second editorial review: Prior to publication, the IPSS Cureus channel editors and the Cureus editor again review the manuscript, this time focusing on the reviewers' comments and the authors' responses. Both also make a final copy edit to meet the requirements of the PubMed Central indexing service. Again, the manuscript must pass both editorial reviews to be approved for publication.

4. Publication process: When a manuscript has been approved for publication, a final migration from the Cureus editing system to permanent storage takes place and a digital object identifier (DOI) number is assigned to the paper. Once a paper has a unique DOI, it is considered 


\section{Cureus}

published and is available on the Cureus.com online journal.

The Cureus Scholarly Impact Quotient ${ }^{\mathrm{TM}}\left(\mathrm{SIQ}^{\mathrm{TM}}\right)$ was examined for each article. The SIQ ${ }^{\mathrm{TM}}$ is assigned by Cureus members' ranking of the article on a ten-point Likert scales [3]. The SIQ ${ }^{\mathrm{TM}}$ assigns a point value from 1 to 10 in each of the: clarity of background and rationale, clinical importance, study design and methods, data analysis, the novelty of conclusions, and quality of presentation. The assigned scores are averaged to reach an overall $\mathrm{SIQ}^{\mathrm{TM}}$ value. The $\mathrm{SIQ}^{\mathrm{TM}}$ is not displayed until at least two members of the Cureus community have provided their evaluation.

Publication impact metrics for each publication, including the number of times each article was cited and in which journals, were collected using Google Scholar (GS) and Web of Science (WOS) [2,4]. The "latency period" - i.e., the time between publication a given work and the publication of the first article to cite that work - was also analyzed. Our assumption was that a shorter latency period was associated with a higher impact publication. Because some published sources do not provide the exact date of publication, the authors employed a consistent method for estimating the citation's publication date. In calculating the date of publication when only the month and year were provided, the date was set to the first day of the calendar month. In the one case where only the year was provided, June 1st of that year was used [5].

\section{Statistical analysis}

Data were analyzed using descriptive statistics. Numeric data are provided using percentages (\%), means, and standard deviations (SD).

\section{Results}

A total of 15 articles by 12 first authors were published on the IPSS Cureus channel during the study period. Ten articles $(66 \%)$ were original articles (OA), four (27\%) were technical reports (TR), and one (7\%) was a review article (RA). The complete list of channel publications can be found in Table 1 .

Burns R, Adler M, Mangold K, \& Trainor J. (2016). A Brief Boot Camp for 4th-Year Medical Students Entering into Pediatric and Family Medicine Residencies. Cureus, 8(2). Retrieved from https://www.cureus.com/articles/4036-abrief-boot-camp-for-4th-year-medical-students-entering-into-pediatric-and-family-medicine-residencies [6].

Collins K, Hopkins A, Shilkofski N. A, Levine R. B, \& Hernandez R. G. (2018). Difficult Patient Encounters: Assessing Pediatric Residents' Communication Skills Training Needs. Cureus, 10(9). Retrieved from https://www.cureus.com/articles/13346-difficult-patient-encounters-assessing-pediatric-residents-communicationskills-training-needs [7].

Doherty E, Rachwal C, Lindamood K, O’Brien C, \& Weinstock P. (2014). Using Simulated Transport Calls to Identify Diversity of Knowledge and Care Plans among the Multidisciplinary Team. Cureus, 6(10). Retrieved from https://www.cureus.com/articles/2661-using-simulated-transport-calls-to-identify-diversity-of-knowledge-and-careplans-among-the-multidisciplinary-team [8].

Mackinnon R, Aitken D, \& Humphries C. (2015). Exploring Mechanisms for Effective Technology-Enhanced Simulation-based Education in Wilderness Medicine: A Systematic Review. Cureus, 7(12). Retrieved from https://www.cureus.com/articles/3342-exploring-mechanisms-for-effective-technology-enhanced-simulationbased-education-in-wilderness-medicine-a-systematic-review [9]. 


\section{Cureus}

Mackinnon R, \& Gough S. (2014). What Can We Learn About Debriefing From Other High-Risk/High-Stakes Industries? Cureus, 6(4). Retrieved from https://www.cureus.com/articles/2472-what-can-we-learn-aboutdebriefing-from-other-high-riskhigh-stakes-industries [10].

Mathieson S, Whalen D, \& Dubrowski A. (2015). Infant Trauma Management in the Emergency Department: An Emergency Medicine Simulation Exercise. Cureus, 7(9). Retrieved from https://www.cureus.com/articles/2961infant-trauma-management-in-the-emergency-department-an-emergency-medicine-simulation-exercise [11].

Peacock P. J, Woodman A, Mccay W, \& Bates S. E. (2016). Resuscitation of the Newborn: Simulating for Confidence. Cureus, 8(9). Retrieved from https://www.cureus.com/articles/4951-resuscitation-of-the-newbornsimulating-for-confidence. [12].

Roberts J, Sawyer T, Foubare D, Reid J, Stone K, Stephanian D, \& Thompson D. (2015). Simulation to Assist in the Selection Process of New Airway Equipment in a Children's Hospital. Cureus, 7(9). Retrieved from https://www.cureus.com/articles/3154-simulation-to-assist-in-the-selection-process-of-new-airway-equipment-in-achildrens-hospital [13].

Rosen O, \& Angert R. M. (2017). Gastroschisis Simulation Model: Pre-surgical Management Technical Report. Cureus, 9(3). Retrieved from https://www.cureus.com/articles/6225-gastroschisis-simulation-model-pre-surgicalmanagement-technical-report [14].

Sawyer T, Gray M, Hendrickson M, Jacobson E, \& Umoren R. (2018). A Real Human Umbilical Cord Simulator Model for Emergency Umbilical Venous Catheter Placement Training. Cureus, 10(11). Retrieved from https://www.cureus.com/articles/15472-a-real-human-umbilical-cord-simulator-model-for-emergency-umbilicalvenous-catheter-placement-training [15].

Sawyer T, \& Strandjord T. (2014). Simulation-based Procedural Skills Maintenance Training for NeonatalPerinatal Medicine Faculty. Cureus, 6(4). Retrieved from https://www.cureus.com/articles/2476-simulation-basedprocedural-skills-maintenance-training-for-neonatal-perinatal-medicine-faculty [16].

Shea K. L, \& Rovera E. J. (2015). Vaginal Examination Simulation Using Citrus Fruit to Simulate Cervical Dilation and Effacement. Cureus, 7(9). Retrieved from https://www.cureus.com/articles/3061-vaginal-examinationsimulation-using-citrus-fruit-to-simulate-cervical-dilation-and-effacement [17].

Starr M, Sawyer T, Jones M, Batra M, \& Mcphillips H. (2017). A Simulation-based Quality Improvement Approach to Improve Pediatric Resident Competency with Required Procedures. Cureus, 9(6). Retrieved from https://www.cureus.com/articles/6940-a-simulation-based-quality-improvement-approach-to-improve-pediatricresident-competency-with-required-procedures [18].

Taras J, \& Everett T. (2017). Rapid Cycle Deliberate Practice in Medical Education - a Systematic Review. Cureus, 9(4). Retrieved from https://www.cureus.com/articles/6528-rapid-cycle-deliberate-practice-in-medicaleducation---a-systematic-review [19].

Zaveri P. P, Davis A. B, O'connell K. J, Willner E, Schinasi D. A, \& Ottolini M. (2016). Virtual Reality for Pediatric Sedation: A Randomized Controlled Trial Using Simulation. Cureus, 8(2). Retrieved from https://www.cureus.com/articles/3622-virtual-reality-for-pediatric-sedation-a-randomized-controlled-trial-usingsimulation [20].

\section{TABLE 1: Articles and types of articles published on the IPSS Cureus channel - 2014- 2018}

OA: original article, RA: review article, TR: technical report, IPSS: International Pediatric Simulation Society 


\section{Cureus}

The number of publications peaked in 2015. See Figure 1. In each case, the authorship was specific to a single country; no group of authors spanned two or more countries. Ten articles were produced by people affiliated to US institutions, three were from the UK, and two were authored by individuals associated with the Canadian universities and medical centers.

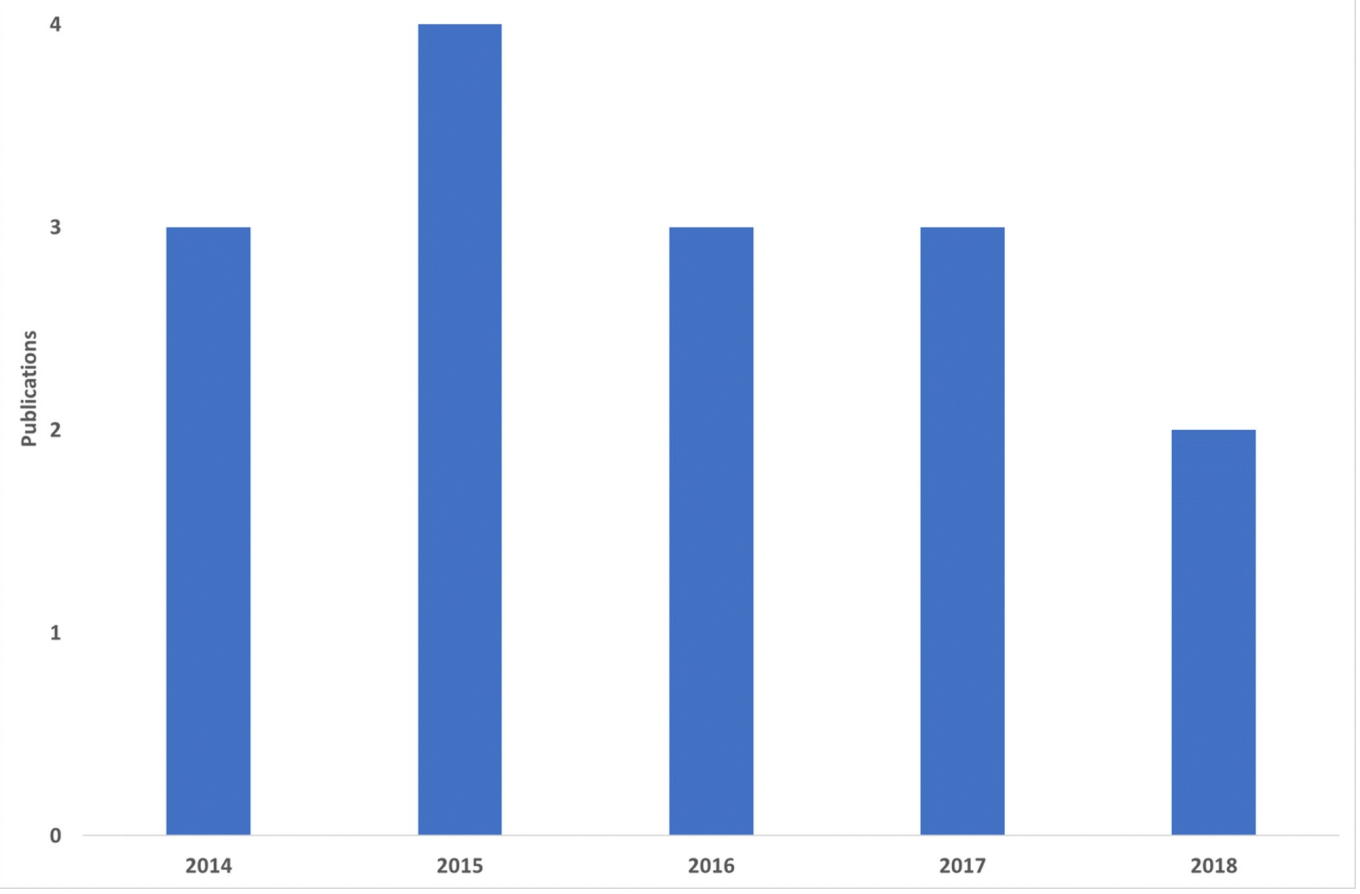

FIGURE 1: Publications per year on the IPSS Cureus Channel

IPSS: International Pediatric Simulation Society

\section{Views and downloads}

The 15 articles were viewed a total of 11,045 times for an average of 736 views per article (SD: 1102) and downloaded in PDF format a total of 6,690 times, averaging 446 downloads per article (SD: 234) during the period of study. The highest number of views for a single article was 4,270 [16]. The highest number of downloads for a single article was 915 [17].

The views per day and downloads per day for each article are provided in Figure 2. The mean views per day was 0.7 (SD: 0.6). The mean downloads per day was 0.5 (SD 0.1). The authors further checked if there was a difference in the viewing and download rates between the types of articles published. Because only one RA had been published during the study period, the results are inconclusive, but no appreciable difference was noted between the OA and TR types in either the viewing or downloading rates. See Table 2. 


\section{Cureus}

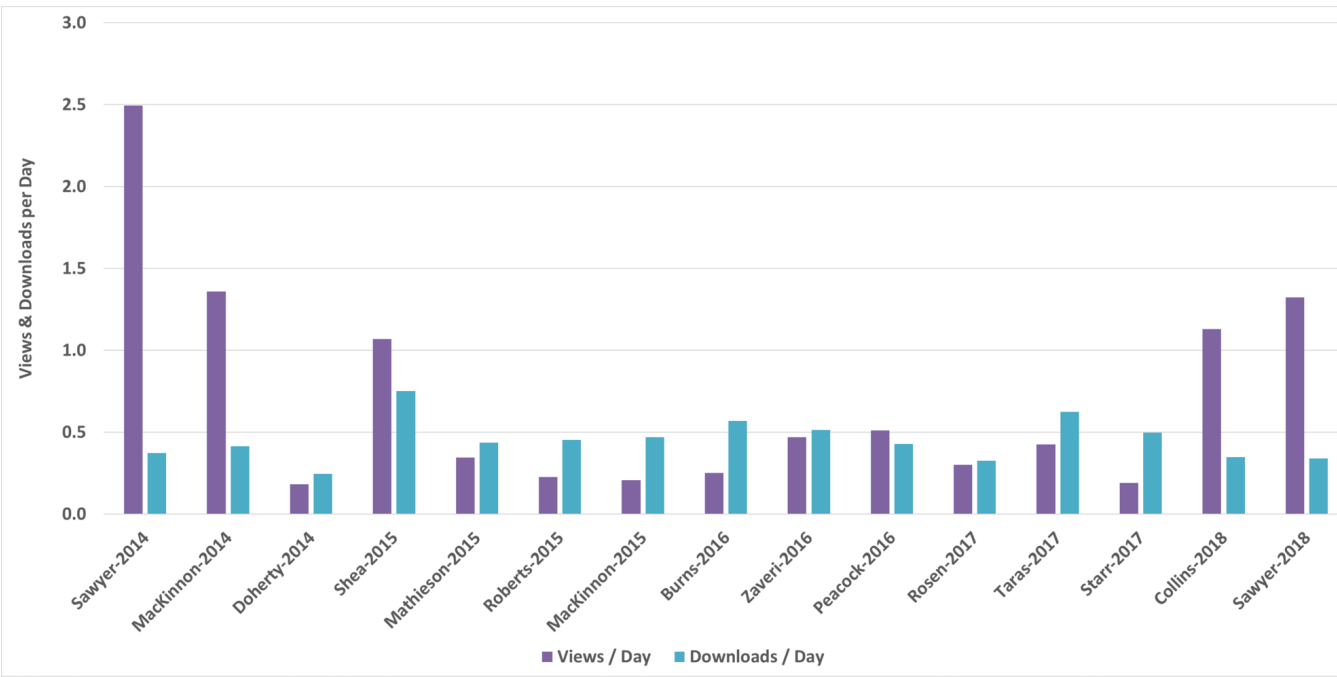

FIGURE 2: Views per day and downloads per day for each article on the IPSS Cureus channel

IPSS: International Pediatric Simulation Society

\begin{tabular}{|c|c|c|c|c|c|c|c|}
\hline All Articles & Published & Type & $\begin{array}{l}\text { Total } \\
\text { Views }\end{array}$ & $\begin{array}{l}\text { Total } \\
\text { Downloads }\end{array}$ & $\begin{array}{l}\text { Days } \\
\text { Active }\end{array}$ & $\begin{array}{l}\text { Views I } \\
\text { Day }\end{array}$ & $\begin{array}{l}\text { Downloads / } \\
\text { Day }\end{array}$ \\
\hline Sawyer-2014 [16] & 4/23/2014 & $\mathrm{OA}$ & 4270 & 640 & 1713 & 2.5 & 0.4 \\
\hline $\begin{array}{l}\text { MacKinnon-2014 } \\
{[10]}\end{array}$ & 4/25/2014 & OA & 2324 & 708 & 1711 & 1.4 & 0.4 \\
\hline Doherty-2014 [8] & 10/9/2014 & OA & 282 & 384 & 1544 & 0.2 & 0.2 \\
\hline Shea-2015 [17] & 9/1/2015 & TR & 1303 & 915 & 1217 & 1.1 & 0.8 \\
\hline $\begin{array}{l}\text { Mathieson-2015 } \\
\text { [11] }\end{array}$ & 9/7/2015 & TR & 419 & 529 & 1211 & 0.3 & 0.4 \\
\hline Roberts-2015 [13] & 9/24/2015 & OA & 271 & 543 & 1194 & 0.2 & 0.5 \\
\hline $\begin{array}{l}\text { MacKinnon-2015 } \\
\text { [9] }\end{array}$ & 12/17/2015 & $O A$ & 230 & 521 & 1110 & 0.2 & 0.5 \\
\hline Burns-2016 [6] & 2/9/2016 & $\mathrm{OA}$ & 265 & 603 & 1056 & 0.3 & 0.6 \\
\hline Zaveri-2016 [20] & 2/9/2016 & OA & 494 & 542 & 1056 & 0.5 & 0.5 \\
\hline Peacock-2016 [12] & 9/20/2016 & OA & 425 & 356 & 832 & 0.5 & 0.4 \\
\hline Rosen-2017 [14] & 3/22/2017 & TR & 195 & 214 & 649 & 0.3 & 0.3 \\
\hline Taras-2017 [19] & 4/19/2017 & RA & 265 & 389 & 621 & 0.4 & 0.6 \\
\hline Starr-2017 [18] & 6/3/2017 & $\mathrm{OA}$ & 110 & 288 & 576 & 0.2 & 0.5 \\
\hline Collins-2018 [7] & 9/21/2018 & $\mathrm{OA}$ & 116 & 38 & 101 & 1.1 & 0.4 \\
\hline
\end{tabular}




\section{Cureus}

\begin{tabular}{|c|c|c|c|c|c|c|c|}
\hline \multirow[t]{5}{*}{ Sawyer-2018 [15] } & $11 / 5 / 2018$ & TR & 76 & 20 & 56 & 1.4 & 0.4 \\
\hline & & Total & 11045 & 6690 & & & \\
\hline & & Mean & 736 & 446 & 976 & 0.7 & 0.5 \\
\hline & & SD & 1102 & 234 & 491 & 0.6 & 0.1 \\
\hline & & Median & 271 & 521 & 1056 & 0.4 & 0.4 \\
\hline Original Articles & Published & Туре & $\begin{array}{l}\text { Total } \\
\text { Views }\end{array}$ & $\begin{array}{l}\text { Total } \\
\text { Downloads }\end{array}$ & $\begin{array}{l}\text { Days } \\
\text { Active }\end{array}$ & $\begin{array}{l}\text { Views / } \\
\text { Day }\end{array}$ & $\begin{array}{l}\text { Downloads / } \\
\text { Day }\end{array}$ \\
\hline Sawyer-2014 [16] & 4/23/2014 & OA & 4270 & 640 & 1713 & 2.5 & 0.4 \\
\hline $\begin{array}{l}\text { MacKinnon-2014 } \\
{[10]}\end{array}$ & 4/25/2014 & OA & 2324 & 708 & 1711 & 1.4 & 0.4 \\
\hline Doherty-2014 [8] & $10 / 9 / 2014$ & OA & 282 & 384 & 1544 & 0.2 & 0.2 \\
\hline Roberts-2015 [13] & 9/24/2015 & $\mathrm{OA}$ & 271 & 543 & 1194 & 0.2 & 0.5 \\
\hline $\begin{array}{l}\text { MacKinnon-2015 } \\
\text { [9] }\end{array}$ & 12/17/2015 & OA & 230 & 521 & 1110 & 0.2 & 0.5 \\
\hline Burns-2016 [6] & 2/9/2016 & OA & 265 & 603 & 1056 & 0.3 & 0.6 \\
\hline Zaveri-2016 [20] & 2/9/2016 & OA & 494 & 542 & 1056 & 0.5 & 0.5 \\
\hline Peacock-2016 [12] & 9/20/2016 & $\mathrm{OA}$ & 425 & 356 & 832 & 0.5 & 0.4 \\
\hline Starr-2017 [18] & 6/3/2017 & OA & 110 & 288 & 576 & 0.2 & 0.5 \\
\hline \multirow[t]{5}{*}{ Collins-2018 [7] } & $9 / 21 / 2018$ & $\mathrm{OA}$ & 116 & 38 & 101 & 1.1 & 0.4 \\
\hline & & Total & 8787 & 4623 & & & \\
\hline & & Mean & 879 & 462 & 1089 & 0.7 & 0.4 \\
\hline & & SD & 1290 & 189 & 480 & 0.7 & 0.1 \\
\hline & & Median & 277 & 532 & 1083 & 0.4 & 0.4 \\
\hline Technical Reports & Published & Type & $\begin{array}{l}\text { Total } \\
\text { Views }\end{array}$ & $\begin{array}{l}\text { Total } \\
\text { Downloads }\end{array}$ & $\begin{array}{l}\text { Days } \\
\text { Active }\end{array}$ & $\begin{array}{l}\text { Views / } \\
\text { Day }\end{array}$ & $\begin{array}{l}\text { Downloads / } \\
\text { Day }\end{array}$ \\
\hline Shea-2015 [17] & 9/1/2015 & TR & 1303 & 915 & 1217 & 1.1 & 0.8 \\
\hline $\begin{array}{l}\text { Mathieson-2015 } \\
\text { [11] }\end{array}$ & 9/7/2015 & TR & 419 & 529 & 1211 & 0.3 & 0.4 \\
\hline Rosen-2017 [14] & 3/22/2017 & TR & 195 & 214 & 649 & 0.3 & 0.3 \\
\hline \multirow[t]{4}{*}{ Sawyer-2018 [15] } & 11/5/2018 & TR & 76 & 20 & 56 & 1.4 & 0.4 \\
\hline & & Total & 1993 & 1678 & & & \\
\hline & & Mean & 498 & 420 & 783 & 0.8 & 0.5 \\
\hline & & SD & 481 & 339 & 479 & 0.5 & 0.2 \\
\hline
\end{tabular}




\section{Cureus}

\section{The publication cycle}

The mean number of days between submission to publication was 46 days (SD: 28). The mean number of days spent in the first editorial review was 11 (SD 12). The mean number of days spent in peer review was 22 (SD: 20). The mean number of days spent in the second editorial review was 12 (SD: 12). The mean number of days spent in the publication process was one (SD: 2). A graph showing the time each article spent in each of the phases can be found in Figure 3. On average, the peer review phase accounted for $48 \%$ of the publication process.

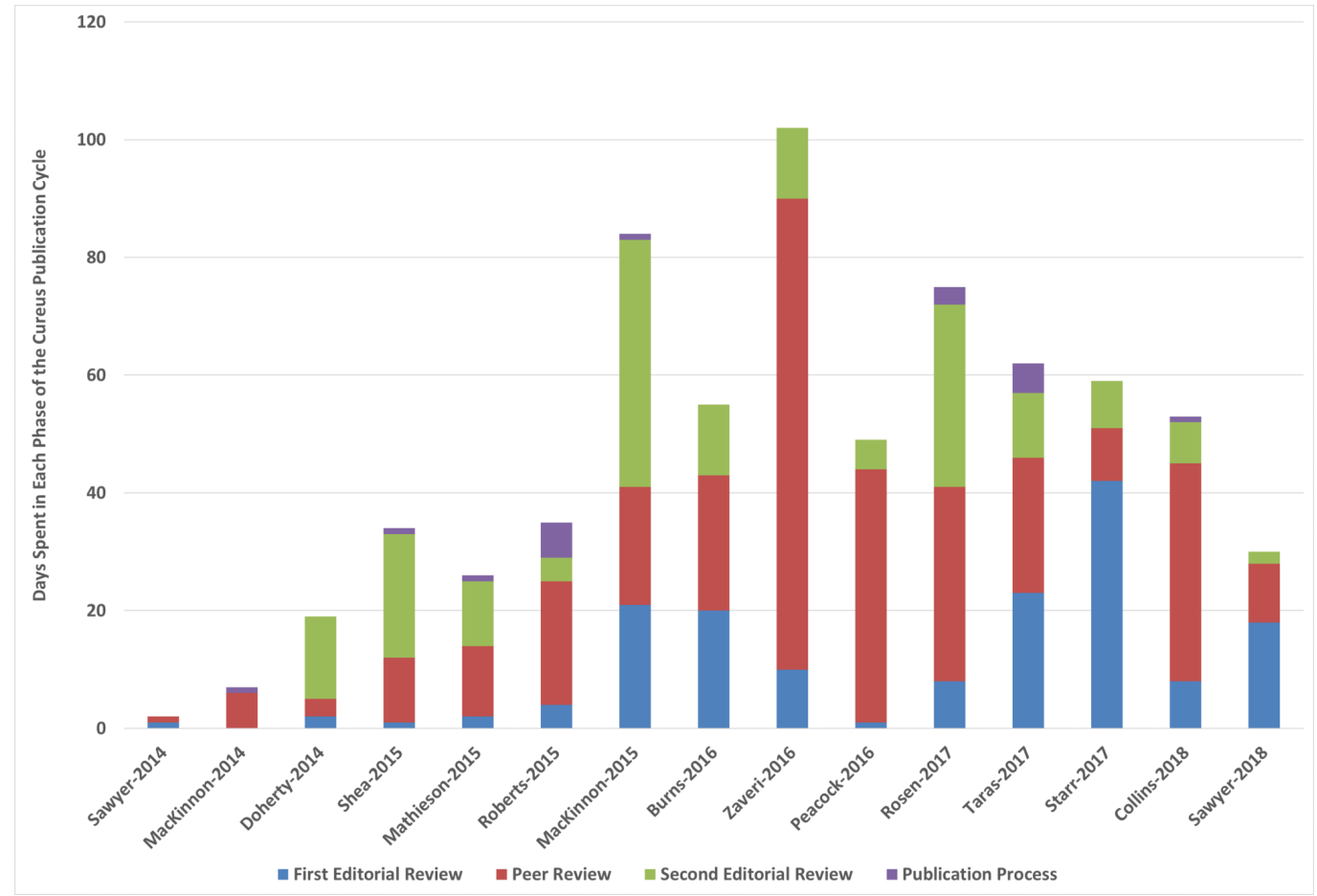

FIGURE 3: Time spent in each of the four Cureus publication cycle phases

\section{Scholarly impact quotient ${ }^{\mathrm{TM}}$}

Of the 15 articles, only six have achieved the required two rankings to receive a $\mathrm{SIQ}^{\mathrm{TM}}[10,11,13,16,19-20]$. Only one had four rankings [13]. All six of the ranked articles were rated above the midpoint score of 5.0 on the ten-point scale, with a mean score of 6.7 (SD: 0.8 ).

\section{Impact analysis}

The 15 articles were cited a total of 36 times (average 2.5 citations per article). The citations are presented in Table 3, and the distribution of citations is shown in Figure 4. 


\section{Cureus}



FIGURE 4: Citation counts for articles published on the IPSS Cureus channel

The global reach of the IPSS Cureus channel can be estimated from the countries where the citations originated, and the languages used in the cited articles. Table 3 shows that while most of the citing sources originated in the United States and English was the predominant language, four of the citing articles were written in Spanish, two in Portuguese, and one each in Arabic and Ukrainian.

\section{Published In / By}

7th International Conference on Information, Intelligence, Systems Applications (IISA)

Academic Pediatrics

Advances in Simulation

American Heart Association

American Journal of Medical Quality

Annals of Emergency Medicine

ARS MEDICA Revista de Ciencias Médicas

Australasian Emergency Care

BMJ Simulation and Technology Enhanced Learning

Clinical Pediatric Emergency Medicine

Comprehensive Healthcare Simulation: Pediatrics (Book)

Cureus

\section{Country}

USA

USA

Switzerland

USA

USA

USA

Chile

Australia

UK

UK

Switzerland

USA

\section{Language}

English

English

English

English

English

English

Spanish

English

English

English

English

English 


\section{Cureus}

Doctoral dissertation

Dominican Republic: Ministry of Public Health (Written Protocol for Care)

Healthcare Simulation Education Evidence: Theory and Practice. (Book)

International Journal of Radiation Oncology*Biology*Physics

Jornal de Pediatria

Journal for Nurses in Professional Development

Journal of Medical Imaging and Radiation Sciences

Journal of Pediatric Surgery

Medicni perspektivi (Medical Perspectives)

Medical Science Educator

Midwifery

Otolaryngologic Clinics of North America

Paediatrics \& Child Health

Proceedings of the 1st International Conference: New Perspectives in Electrical \&

Computer Engineering

Revista Española de Anestesiología y Reanimación

Revista Española de Pediatría

Revista Multidisciplinar e de Psicologia

Seminars in Fetal and Neonatal Medicine

Seminars in Perinatology

Simulation in Healthcare

Society for Teachers of Family Medicine Spring Conference (Poster)

Southern Medical Journal

Technology and Health Care
UK

English

Dominican

Republic

Spanish

UK

English

The Netherlands

English

Brazil

Portuguese

USA

English

The Netherlands

English

USA

English

Ukraine

Ukrainian

USA

English

USA

English

UK

English

Canada

English

Morocco

Arabic

Spain

Spanish

Spain

Spanish

Brazil

The Netherlands

UK

USA

English

USA

English

USA

English

The Netherlands

English

\section{TABLE 3: Source publications where citations appeared, home country of publication,}

and original language

Figure 5 shows the latency periods for each article cited. The mean latency period for the 11 articles cited was 437 days (SD: 274 days). The longest latency period was 923 days, while the shortest latency period was 174 days $[16,20]$. 


\section{Cureus}

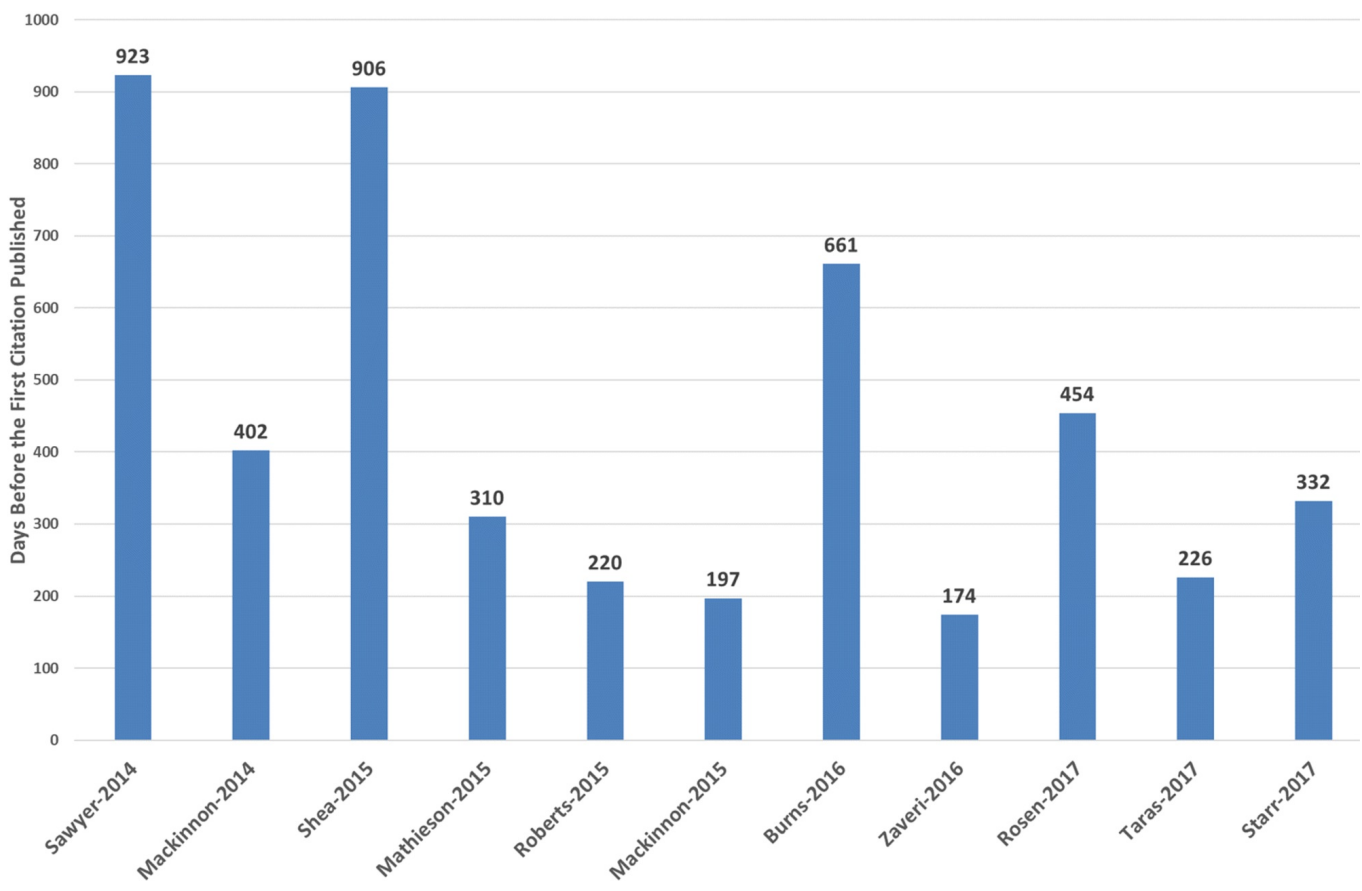

FIGURE 5: Citation latency period for each cited article on the IPSS Cureus channel

IPSS: International Pediatric Simulation Society

\section{Discussion}

Our analysis shows an overall low level of publication activity on the IPSS Cureus channel with only 15 publications over 55 months. Publications on the channel have decreased over time, further indicating that the channel is underused by IPSS members. Published articles, however, appear to have a large impact regarding views, downloads, and citations. TRs compare favorably to original articles in terms of views and downloads, being viewed and downloaded slightly more than original articles. Increased member awareness may increase article submissions. We hope that providing this detailed analysis of the impact of articles on the IPSS Cureus channel will foster more interest in using the channel by IPSS members.

Because a relatively small number of articles have been published on the IPSS Cureus channel over the past 55 months, performing anything beyond a descriptive analysis was not possible. However, we feel our analysis uncovered some interesting points. First, 11 of the articles had a wide impact, both in terms of the journals and other publications that cited them, but also through the authorship of the articles citing them. All the articles published on the channel were authored by groups within the same country and mostly within the same institutions. The sources that cited them, however, showed a far greater international variety. Six of the 37 citations to IPSS Cureus channel publications were authored by international teams. Eight sources were originally published in languages other than English from countries ranging from Spain, Chile, and the Dominican Republic (Spanish) to Brazil (Portuguese) to Morocco (Arabic) and Ukraine (Ukrainian). In one case, a citation to an IPSS Cureus channel publication was from a protocol on the treatment of gastroschisis, a rare birth defect, issued by the Ministry of Public Health of the Dominican Republic [21].

The statistics on views and download rates per day presented some noteworthy anomalies. The 
most viewed article was the first one published on the channel [16]. This would be expected since it has been available longer than any other article, but the views per day (2.5) were almost twice that of the next highest number of views per day $(1.4)[10,15]$. The authors are unable to fully explain this phenomenon.

The most downloaded article was a TR from 2015 with 915 downloads during the study period or a mean of 0.8 downloads per day [17]. This was $25 \%$ more than the next highest number of downloads per day of $0.6[6,19]$. The high rate of download may be partially explained by the nature of the TR itself, which described a simple, inexpensive method of simulating vaginal dilation and effacement. That type of TR may have attracted significant attention in low resource areas of the world. Unfortunately, the authors had no data on where the downloads originated, and hence, they could not test this hypothesis.

This study has several limitations. The lack of data on where views and downloads originate limits the ability to measure the overall global impact of the publications on the IPSS Cureus channel. Other limitations of this study include the lack of any comparison group of articles from outside the channel and the small population of articles being studied. Finally, the lack of data on views and downloads over time limits the ability to make inferences regarding the sustained interest in each article.

\section{Conclusions}

Our analysis of the IPSS Cureus channel publication activity shows that publications on the channel have a clear impact. The channel offers a rapid submission-to-publication cycle with an average publication turn-around of less than two months, faster than most other peerreviewed medical journals.

The next step in the analysis of the IPSS Cureus channel will be to determine a reference collection of Cureus articles to use as a control group and then reevaluate the impact of the channel against that of the comparison group. A complete bibliometric examination of the Cureus journal might also show interesting trends and present further support for the Cureus model of medical information dissemination.

\section{Additional Information \\ Disclosures}

Human subjects: All authors have confirmed that this study did not involve human participants or tissue. Animal subjects: All authors have confirmed that this study did not involve animal subjects or tissue. Conflicts of interest: In compliance with the ICMJE uniform disclosure form, all authors declare the following: Payment/services info: All authors have declared that no financial support was received from any organization for the submitted work. Financial relationships: All authors have declared that they have no financial relationships at present or within the previous three years with any organizations that might have an interest in the submitted work. Other relationships: All authors have declared that there are no other relationships or activities that could appear to have influenced the submitted work.

\section{References}

1. National Center for Biotechnology Information. Home - PMC - NCBI . (2019). Accessed: January 17, 2019: https://www.ncbi.nlm.nih.gov/pmc/.

2. Web of Science, Clarivate. (2018). Accessed: December 29, 2018: https://clarivate.com/products/web-of-science/.

3. Cureus | Scholarly Impact Quotient (SIQ). (2018). Accessed: December 27, 2018: https://www.cureus.com/siq. 
4. Google Scholar. (2018). Accessed: December 29, 2018: https://scholar.google.com/.

5. Gough S: The use of simulation-based education in cardio-respiratory physiotherapy . Doctoral dissertation. Manchester Metropolitan University, Manchester, UK. 2016, https://espace.mmu.ac.uk/617694.

6. Burns R, Adler M, Mangold K, Trainor K: A brief boot camp for 4th-year medical students entering into pediatric and family medicine residencies. Cureus. 2016, 8:e488.

10.7759/cureus.488

7. Collins K, Hopkins A, Shilkofski NA, Levine RB, Hernandez RG: Difficult patient encounters: assessing pediatric residents' communication skills training needs. Cureus. 2018, 10:e3340. 10.7759/cureus.3340

8. Doherty E, Rachwal C, Lindamood K, O’Brien C, Weinstock P: Using simulated transport calls to identify diversity of knowledge and care plans among the multidisciplinary team. Cureus. 2014, 6:e217. 10.7759/cureus.217

9. Mackinnon R, Aitken D, Humphries C: Exploring mechanisms for effective technologyenhanced simulation-based education in wilderness medicine: a systematic review. Cureus. 2015, 7:e412. 0.7759/cureus.412

10. Mackinnon R, Gough S: What can we learn about debriefing from other high-risk/high-stakes industries?. Cureus. 2014, 6:e174. 10.7759/cureus.174

11. Mathieson S, Whalen D, Dubrowski A: Infant trauma management in the emergency department: an emergency medicine simulation exercise. Cureus. 2015, 7:e316. 10.7759/cureus.316

12. Peacock PJ, Woodman A, Mccay W, Bates SE: Resuscitation of the newborn simulating for confidence. Cureus. 2016, 8:e790. 10.7759/cureus.790

13. Roberts J, Sawyer T, Foubare D, et al.: Simulation to assist in the selection process of new airway equipment in a children's hospital. Cureus. 2015, 7:e331. 10.7759/cureus.331

14. Rosen O, Angert RM: Gastroschisis simulation model: pre-surgical management technical report. Cureus. 2017, 9:e1109. 10.7759/cureus.1109

15. Sawyer T, Gray M, Hendrickson M, Jacobson E, Umoren R: A real human umbilical cord simulator model for emergency umbilical venous catheter placement training. Cureus. 2018, 10:e3544. 10.7759/cureus.3544

16. Sawyer T, Strandjord T: Simulation-based procedural skills maintenance training for neonatal-perinatal medicine faculty. Cureus. 2014, 6:e173. 10.7759/cureus.173

17. Shea KL, Rovera EJ: Vaginal examination simulation using citrus fruit to simulate cervical dilation and effacement. Cureus. 2015, 7:e314. 10.7759/cureus.314

18. Starr M, Sawyer T, Jones M, Batra M, Mcphillips H: A simulation-based quality improvement approach to improve pediatric resident competency with required procedures. Cureus. 2017, 9:e1307. 10.7759/cureus.1307

19. Taras J, Everett T: Rapid cycle deliberate practice in medical education - a systematic review . Cureus. 2017, 9:e1180. 10.7759/cureus.1180

20. Zaveri PP, Davis AB, O’Connell KJ, Willner E, Schinasi DA, Ottolini M: Virtual reality for pediatric sedation: a randomized controlled trial using simulation. Cureus. 2016, 8:e486. 10.7759 /cureus.486

21. Vásquez FN: Protocolo de Atención para el Tratamiento de la Gastroquisis en Neonatos . Ministry of Public Health, Santo Domingo, N.D, Dominican Republic. 2018, 1:1-22. Accessed: 2018-12-15: http://www.msp.gob.do/oai/documentos/Convocatorias/2018/Septiembre/MISPAS-DAF-CM2018-0204/Protocolo\%20de\%20\%20Gastro.... 